\title{
Survey on roof movement of the gangue backfill working face
}

\author{
Guangjing Sun ${ }^{1}$, Tao Feng ${ }^{2}$, Jinhai Liu ${ }^{3}$ \\ ${ }^{1,2}$ School of Resources, Environment and Safety Engineering, Hunan University of Science and \\ Technology, Xiangtan, China \\ ${ }^{1}$ Shandong Energy Xinwen Mining Group Co., Xintai, China \\ ${ }^{3}$ Safety Engineering College, North China Institute of Science and Technology, Beijing, China \\ ${ }^{2}$ Corresponding author \\ E-mail: 12038995876@qq.com, ${ }^{2}$ tfeng@hnust.edu.cn, ${ }^{3}$ jh_liu1982@163.com
}

Received 9 January 2019; received in revised form 3 April 2019; accepted 21 May 2019

DOI https://doi.org/10.21595/jve.2019.20511

Check for updates

Copyright (C) 2019 Guangjing Sun, et al. This is an open access article distributed under the Creative Commons Attribution License, which permits unrestricted use, distribution, and reproduction in any medium, provided the original work is properly cited.

\begin{abstract}
This paper studied the roof movement characteristics of LW1302N-1 with gangue backfill mining in Shandong Xinjulong Company of China. The monitoring of roof subsidence of the gob and bearing stress of filled gangue was carried out by using the roof subsidence and gangue loading monitoring system. From data analysis, the result shows that: (1) Gob roof subsidence can be divided into six stages including slow subsidence, fast subsidence, very fast subsidence, subsidence slowing down, subsidence speeding up and subsidence becoming slow. (2) Filled gangue loading period can be divided into four stages including slow increasing resistance, fast increasing strength, strengthening and continuing increasing resistance, Similarly, the gob roof movement consists of four steps such as immediate roof caving, central roof flexure, main roof fracturing, and high strata flexure. (3) The immediate roof is 3.1 times the thickness of equal mining height, and the main roof is 2.7 times the thickness of equal mining height. The research results provide a reference to the analysis of the characteristics of overlying strata structure and roof movement for gangue backfill mining in deep coal mines.
\end{abstract}

Keywords: gangue filling, overburden structure, roof settling, gangue loading, monitoring.

\section{Introduction}

In recent years, coal gangue backfill mining technology has been widely concerned and applied [1-6]. Its main advantages lie in: (1) Effective control of strata activities, slow down surface subsidence, solve the "three-underground mining" (Mining under special conditions with buildings, railways, and water) coal mining problem. (2) The separation of underground coal gangue implemented, and the separated gangue is filled into the goaf through the underground conveying system so that the underground gangue not lifted and the coal lifting rate of the main shaft increased. (3) Through the surface and underground combined conveying system, the ground gangue filled into the goaf, the gangue hill was eliminated, the pollution of the ground gangue is controlled, and the explosion danger of the ground gangue hill eliminated. Compared with paste filling, hydraulic backfilling and Super-high water filling, gangue filling has the advantages of pure technology, low cost, and high efficiency.

Combined with the practice of gangue backfill mining in coal mines, domestic and foreign scholars have made a lot of research results. Wang Jiachen [7] simulated the filling mining process of longwall gangue and pointed out that the effective resistance of support has a significant influence on filling effect. Zhang Jixiong [8] points out that increasing the elastic modulus of filling material can reduce the bending deformation of principal strata by studying the deformation characteristics of key layers in fully mechanized overburden mining with waste filling, which proves that waste filling mining has the function of limiting the deformation of principal strata and controlling surface subsidence. Miao Xiexing [9-13] analyzed the characteristics of rock pressure in filling drilling with gangue, pointed out that the roof subsidence speed, subsidence and the mining influence range of two roadways in filling mining were significantly lower than those 
in non-filling mining. Zhang Wenhai [14] developed a tail-driven gangue conveyor to improve filling efficiency. Song Zhenqi [15] put forward a green, safe and efficient mining mode of filling gangue without coal pillars. Chen Jie [16] establishes the elastic foundation beam model of the movement of overburden rock in gangue filling mining and obtains the relationship between the maximum surface subsidence and the foundation coefficient of the foundation beam and the subsidence before the roof touches the gangue. Xu Ping et al. [17-20] studied the law of overburden rock fracture development in thick loose bed and thin bedrock solid filling mining, and obtained that the development height of overlying thin bedrock plastic zone was restrained in solid filling mining because of the supporting effect of filling body on overburden rock, thus limiting the development of overburden rock fracture. Miao Xiexing [21] has developed equipment and technology of comprehensive mechanized gangue filling mining system and extended integrated hydraulic support for mining and filling. Zhu Chuanqu [22] points out the compression mechanical properties test of waste filling material, pointing out that the content of the excellent article (particle size $<5 \mathrm{~mm}$ ) should not exceed $30 \%$ when using basic gangue backfill mining. Liu Jiangong [23] took \#7606 working face of Xingtai Coal Mine as the research object, with gangue and fly ash as filling materials, studied the solid filling test under buildings by using self-compacting filling hydraulic support. The research proved that filling body can effectively control the movement of roof and ensure that surface buildings are not affected by mining. Zhanguo Ma et al. [24-27] studied the creep mechanical behavior and macro and micromechanical properties of filling gangue materials. Zhang Q [28] analyzed the mechanical expression of overburden rock in gangue backfill mining. Huang Yanli [29] investigated the control effect of the compaction rate of gangue on the movement of coal seam filled with gangue. $\mathrm{Xu}$ Junming [30] analyzed the deformation characteristics of gangue-fly ash filling material in compaction process, studied the basic deformation law of gangue-fly ash filling material, and concluded that the control effect of strata movement in fully mechanized mining face with filling was good, and basically did not affect the normal use of surface buildings and facilities. Guo Guangli [31] analyzed the subsidence mechanism and process of waste filling mining in longwall working face, put forward the concepts of effective filling thickness and equivalent mining thickness, and established the prediction model of overburden failure and surface subsidence in waste filling mining in longwall working face.

The above research results improve the theory of gangue backfilling mining and promote the popularization and application of gangue backfilling mining technology. However, the research on the movement characteristics of the roof in gangue backfilling mining depends on the idealized mechanical model, and the relevant results obtained have some limitations. Therefore, based on the monitoring of roof settlement and a load of filling gangue in goaf, this paper discusses the roof movement characteristics of filling gangue, expects to consult with colleagues and provides a practical basis for the popularization and application of filling gangue mining technology.

\section{Geological and mining technical conditions}

The No.1302N-1 working face of Xinjulong coal mine is located in the north of first mining air intake uphill at $810 \mathrm{~m}$ level, the No. $1303 \mathrm{~N}$ mined-out area in the east, $1303 \mathrm{~N}$ planned working face in the West and $1302 \mathrm{~N}$ mined-out area in the north. The coal seam of $1302 \mathrm{~N}-1$ working face is No. 3 coal seam, with the average thickness is $3.2 \mathrm{~m}$, the inclination angle is $9-13$ degrees, and the average inclination angle is 11 degrees. The coal seam thickness stability is excellent, the structure is simple, and there is a thin layer of mud-sand inclusion in the upper part. The inclination length of the working face is $80-111 \mathrm{~m}$, with an average range is $94 \mathrm{~m}$, the advancing length is $440 \mathrm{~m}$, and the burial depth is $767-806 \mathrm{~m}$. The geological column of coal seam as shown in Fig. 1 .

The filling gangue of $1302 \mathrm{~N}-1$ working face comes from the underground gangue separation system. The working face applies the comprehensive mechanized coal mining with retrusive strike longwall and second drum shearer to coal cutting at a depth of $0.6 \mathrm{~m}$. Two cycles are completed in one round trip using end oblique cutting method. The backfilling hydraulic support 
ZC9000/20/38 are used to support the roof and backfilling, a coal scraper conveyor placed under the front roof beam, and a filling scraper conveyor suspended under the rear roof beam, A tamping mechanism fixed on the base, The maximum control roof distance is $8.5 \mathrm{~m}$ and the center distance is $1.75 \mathrm{~m}$. The filling is carry out after cutting coal with one knife, and the gangue filled into the goaf is tampered and pressed by tamping mechanism.

\begin{tabular}{|c|c|c|c|}
\hline Lithological & Columnar & Average thickness /m & Lithological description \\
\hline Fine sandstone & & 4.18 & $\begin{array}{l}\text { Light gray, fracture development, } \\
\text { horizontal bedding }\end{array}$ \\
\hline Siltstone & & 19.87 & $\begin{array}{l}\text { Gray, fracture development, partially } \\
\text { fine sandy, partially carbonized, } \\
\text { horizontal bedding, with plant stem } \\
\text { fossils }\end{array}$ \\
\hline Coal & & 3.2 & Fat coal \\
\hline Mudstone & & 1.45 & Gray, pure, crisp \\
\hline Siltstone & & 3.4 & Dark gray, dense \\
\hline
\end{tabular}

Fig. 1. Geological column of coal seam

\section{Layout of monitoring system}

When the $1302 \mathrm{~N}-1$ working face pushed $98 \mathrm{~m}$, the monitoring system of roof settlement and gangue load arranged, and corresponding roof displacement sensor and gangue pressure sensor are arranged behind 37\# supports, as shown in Fig. 2. The roof displacement sensor and the gangue pressure sensor are arranged together and connected to the mine pressure monitoring system through a communication cable. The monitoring data are transmitted to the sub-stations in the belt groove by wireless mode from the sub-stations. Then the monitoring data are transferred to the switch through the communication cable. After the monitoring signal transformed, the monitoring signal transmitted to the ground through the optical fiber.

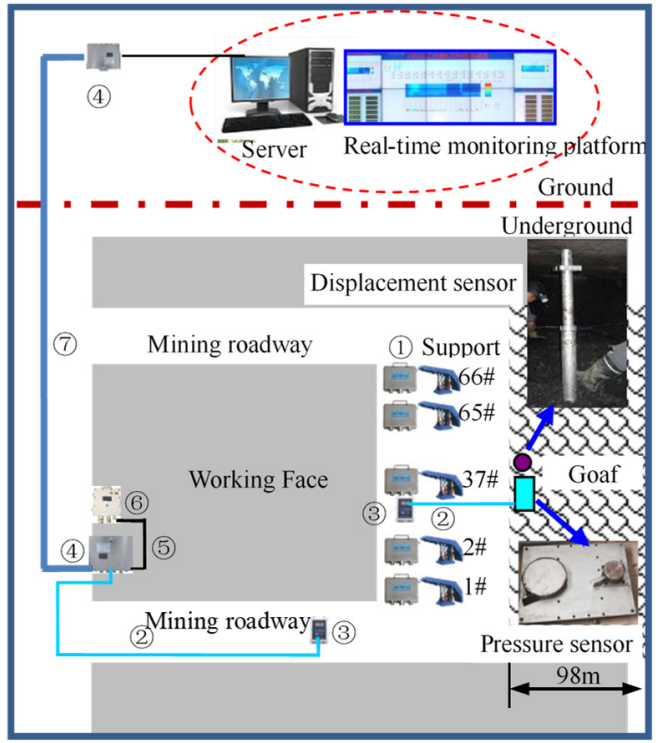

Fig. 2. Underground monitoring system layout: (1) - hydraulic support pressure gauge,

(2) - communication cable, (3) - substation of ground pressure monitoring system, (4) - switch, (5) - power supply cable, (6) - power supply, (7) - optical fiber 
The structure of roof displacement sensor, such as single hydraulic prop (see Fig. 3(a)), uses gear-rack structure to convert linear displacement into angular displacement and converts displacement signal into voltage signal through internal angular displacement sensor with a measuring range of $1500 \mathrm{~mm}$. The gangue load sensor adopts the integrated structure of the load-type strain sensor and signals conditioning circuit, and it has two sensing devices, $2 \mathrm{~T}$ and $20 \mathrm{~T}$ (see Fig. 3(b)). The diameter of the bearing body is $300 \mathrm{~mm}$ and $150 \mathrm{~mm}$ respectively, and the accuracy is $0.1 \mathrm{kN}$ and $1 \mathrm{kN}$ respectively. The roof displacement sensor and the gangue pressure sensor are placed horizontally on the floor and fixed by the bolt.

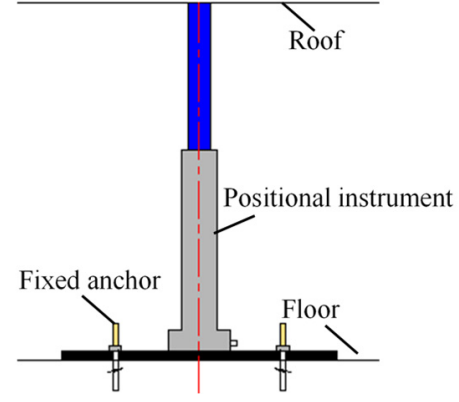

a) Roof displacement sensor

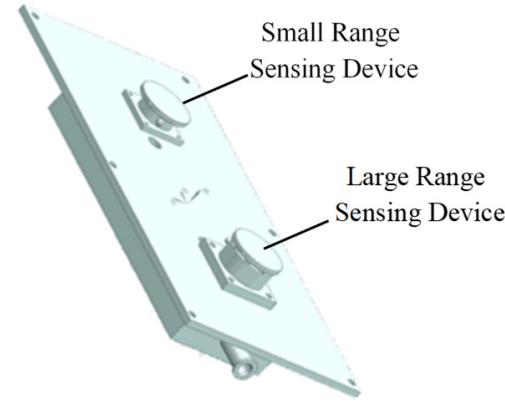

b) Gangue pressure sensor

Fig. 3. Sensor structures of roof displacement and gangue stress

\section{Monitoring data analysis}

Fig. 4 shows the roof settlement curve of goaf. It can see from the figure that the settlement velocity of the roof at the station begins to increase when the station enters the goaf for $24 \mathrm{~m}$. Until it comes to the goaf for $38 \mathrm{~m}$, the roof settlement at the survey station is $150 \mathrm{~mm}$, and the settlement velocity is $10 \mathrm{~mm} / \mathrm{d}$. The arrangement at previous is not apparent. When entering the goaf $38 \mathrm{~m}$, the speed of roof settlement increases again at the station. Until it comes to the goaf for $47 \mathrm{~m}$, the roof settlement at the survey station is $359 \mathrm{~mm}$, and the settlement velocity reached $30 \mathrm{~mm} / \mathrm{d}$. When entering the goaf $47 \mathrm{~m}$, the roof settlement at the survey station becomes slower. Until it comes to the goaf for $78 \mathrm{~m}$, the roof settlement at the survey station is $172 \mathrm{~mm}$, and the settlement velocity is $4.3 \mathrm{~mm} / \mathrm{d}$. When entering the goaf for $78 \mathrm{~m}$, the speed of top subsidence at the station increases again. Until it comes to the goaf for $90 \mathrm{~m}$, the roof settlement at the survey station is $231 \mathrm{~mm}$, and the settlement velocity is $12.2 \mathrm{~mm} / \mathrm{d}$. When entering $90 \mathrm{~m}$ behind the goaf, the roof settlement at the survey station slowed again. During 14 February, the roof settlement was $47 \mathrm{~mm}$, and the settlement velocity was $3.4 \mathrm{~mm} / \mathrm{d}$.

Fig. 5 shows the variation curve of the gangue bearing capacity in the goaf. It can see from the figure that the small-range sensor changes obviously after the station enters the goaf. When the station reached the goaf $11 \mathrm{~m}$, the small-range sensor reaches its maximum range of $20 \mathrm{kN}$, and the large-range sensor changes significantly after the station enters the goaf. When the station came to the goaf $13 \mathrm{~m}$, the support strength of the gangue began to increase rapidly until the station reached the goaf for $18 \mathrm{~m}$. During this period, the support strength of the gangue increased by $0.763 \mathrm{MPa}$ and the growth rate is $0.105 \mathrm{MPa} / \mathrm{d}$. When the station enters the goaf for $18-20 \mathrm{~m}$, the increase rate of the support strength of the gangue becomes slower, and then increases rapidly until the station reached the goaf area for $24 \mathrm{~m}$. During this period, the support strength of the gangue increases by $0.623 \mathrm{MPa}$, and the speed is $0.089 \mathrm{MPa} / \mathrm{d}$. After that, the gangue support strength is increased slowly until the station enters the goaf for $47 \mathrm{~m}$. During this period, the bearing capacity curve of the gangue presents a "step" increasing mode, with a cumulative increase of $0.226 \mathrm{MPa}$ and a growth rate of $0.089 \mathrm{MPa} / \mathrm{d}$. When the station enters the goaf for $47 \mathrm{~m}$, the increase rate of the gangue bearing capacity at the station slightly increase. The gangue support strength at the station reached 2.1 MPa during to 5, December. 


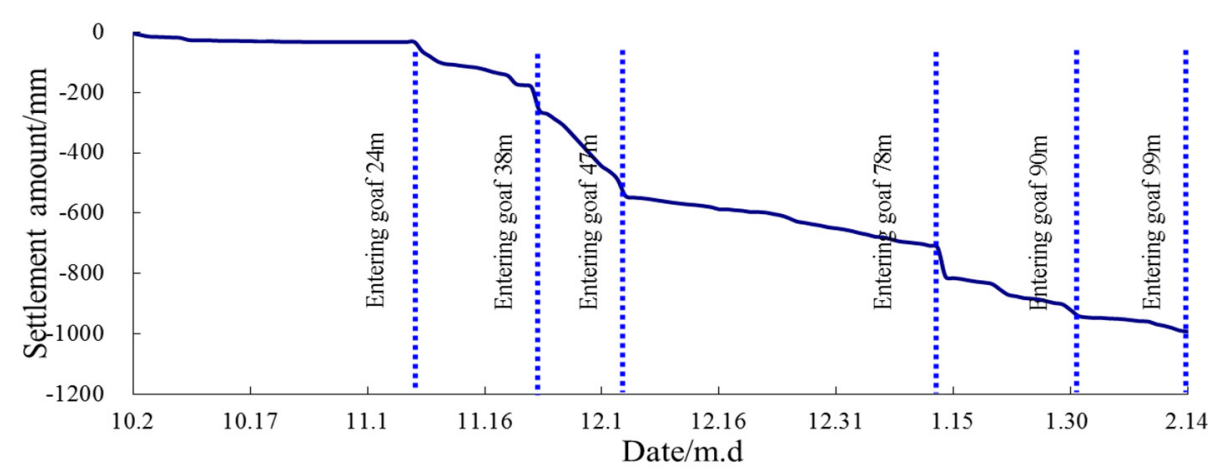

Fig. 4. Curve of roof subsidence in the gob

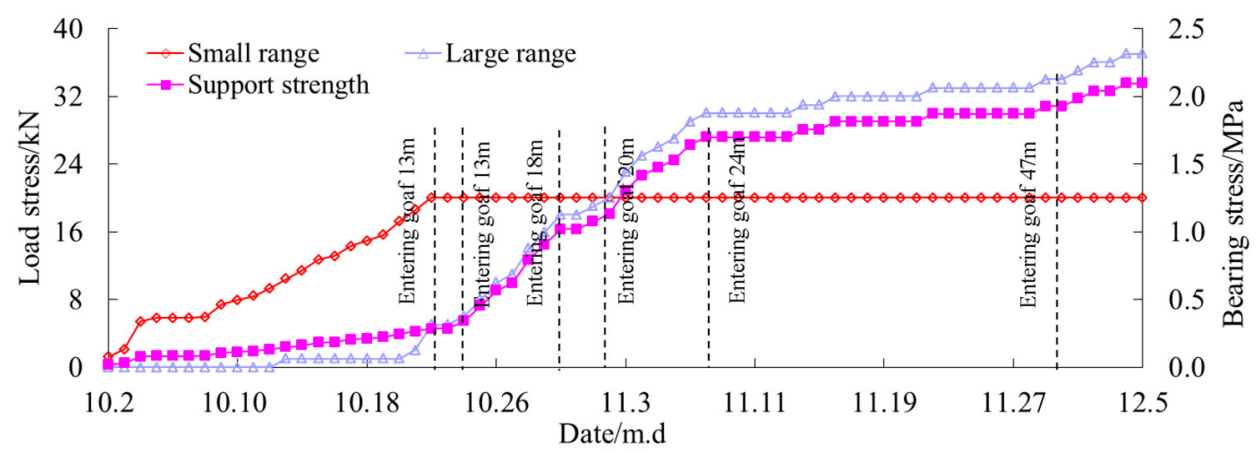

Fig. 5. Curves of bearing stress of the gangue in the gob

Based on the above analysis of the monitoring results of the roof settlement and the bearing capacity of gangue in goaf, it can be concluded that: (1) The roof settlement in goaf can be divided into six stages: slow settlement, rapid settlement, sharp settlement, deceleration of settlement, acceleration of settlement, slowdown of settlement, etc. The corresponding position is $0-24 \mathrm{~m}$, 24-38 m, 38-47 m, 47-78 m, 78-90 m, 90-99 $\mathrm{m}$ in the rear of goaf, respectively. (2) The bearing capacity of gangue in goaf divides into four stages: slow increase resistance, fast increase resistance, strengthening, and continuous increasing resistance. The corresponding position is 0-13 m, 13-24 m, 24-47 m, 47-99 m. (3) The movement of the roof behind goaf can be divided into four stages: Direct roof caving, basic top deflection, central roof breaking settlement and high rock bed deflection. The corresponding position is 0-13 m, 13-24 m, 24-47 m, 47-99 m.

\section{Inference of overburden structure in gangue backfill mining}

The subsidence of roof in the goaf under pressure in real time is $940 \mathrm{~mm}$ for the filling gangue of $1302 \mathrm{~N}-1$ working face. Considering that the mining height of the working face is $3,200 \mathrm{~mm}$, the top connection distance of the filling gangue is about $400 \mathrm{~mm}$, the actual filling gangue height is $2,800 \mathrm{~mm}$, and the compacted gangue height is $2,260 \mathrm{~mm}$, the compaction rate of the filling gangue is $2,260 / 2800=80.7 \%$.

The height of the direct roof caving increases continuously after the measuring station enters the goaf. When the measuring station comes to the goaf for $13 \mathrm{~m}$, the height of the direct roof caving reaches the maximum. At this time, the stress value of the measuring station is $0.283 \mathrm{MPa}$. The loading of the current station is from filling gangue and direct roof caving gangue. The filling of filling gangue is $0.059 \mathrm{MPa}$, while that of direct jacking gangue is $0.244 \mathrm{MPa}$. Considering that in order to facilitate the monitoring of goaf roof settlement, the roof at the measuring station is required not to broken, and the roof strengthened along the strike, the area affected by the direct roof of the sensor at the measuring station is 3 times of the sensor area, so the direct roof thickness 
is $2.87 \mathrm{~m}$.

The measuring station enters the stage of rapid resistance increase of gangue in the range of 13-24 $\mathrm{m}$ in the goaf, and the reason of rapid resistance increase of gangue is that the essential top deflection makes the gangue in a given deformation state, which forces the gangue to be loaded. When the station enters the 24-47 m range of the goaf, the bearing capacity of the gangue is strengthened, and the supporting strength of the gangue increases in a step-by-step manner under the action of the basic roof breaking rotation. When the station enters $47 \mathrm{~m}$ behind the goaf, the basic roof rotation ends. At this time, the settlement of the basic roof and back end is $540 \mathrm{~mm}$. The basic roof is in equilibrium under the action of the backend gangue and the front hydraulic support. The reading of the monitoring sensor of the backend gangue bearing capacity is $1.698 \mathrm{MPa}$. Considering the force exerted by filling gangue and the direct roof falling gangue, the force exerted by the basic roof on gangue is $1.415 \mathrm{MPa}$, and the bearing capacity of gangue is $25 \mathrm{kN}$. At this time, the working resistance of the hydraulic support is $6873.7 \mathrm{kN}$. Considering the basic top lateral width is $1.75 \mathrm{~m}$, the corresponding width of each hydraulic support is $291.6 \mathrm{kN}$. Because of the equilibrium state of the basic roof, it is inferred that the basic roof thickness is $2.56 \mathrm{~m}$.

Based on the above analysis, the characteristics of overburden movement in filling face can be obtained: the height of direct roof caving in 0-13 m back of goaf increases continuously, and the maximum height of direct roof caving is $2.87 \mathrm{~m}$ when the distance is $13 \mathrm{~m}$ from coal wall, the basic roof periodic fracture step is $47 \mathrm{~m}$, the settlement at the contact with gangue is $540 \mathrm{~mm}$, and the thickness is $2.56 \mathrm{~m}$. According to the width of the coal seam returned to $1302 \mathrm{~N}-1$ working face is $3200 \mathrm{~mm}$, the height of filling gangue is $2800 \mathrm{~mm}$, and the height of compaction is $2260 \mathrm{~mm}$, the equivalent mining height [9] is $940 \mathrm{~mm}$. The residual coefficient of bulk increase of direct roof caving gangue is 1.14 after calculation. Therefore, it can be inferred that the overburden structure of gangue filling mining for the $1302 \mathrm{~N}-1$ working face is shown in Fig. 6, in which the direct top thickness is $2.87 \mathrm{~m}$, and the basic top width is $2.56 \mathrm{~m}$, respectively 3.1 times and 2.7 times of the equivalent mining height.

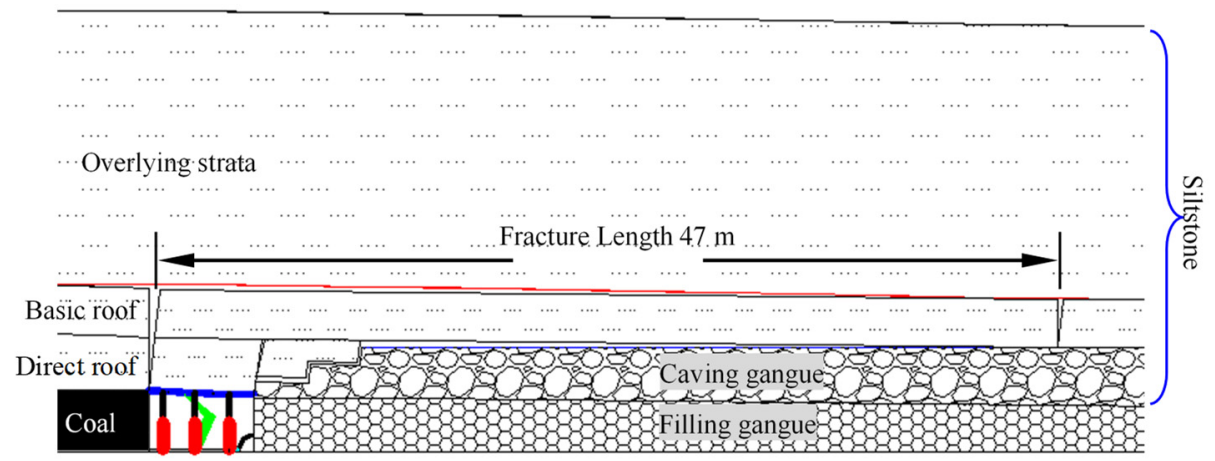

Fig. 6. Overlying strata structure of LW1302N-1 with gangue backfill mining

\section{Conclusions}

Based on the gangue backfill mining in 1302N-1 working face of Shandong Xinjulong Company of China, roof settlement and load monitoring system of waste rock are used to monitor roof displacement and pressure of backfill waste rock in goaf. The movement characteristics of overburden rock in backfill mining of waste rock are analyzed, and the following conclusions are drawn:

1) The roof subsidence of goaf in gangue backfill mining can be divided into six stages: slow subsidence, fast subsidence, very fast subsidence, subsidence slowing down, subsidence speeding up and subsidence becoming slow.

2) Filled gangue loading period can be divided into four stages including slow increasing 
resistance, fast increasing resistance, strengthening and continuing increasing resistance. Accordingly, the gob roof movement consists of four steps such as immediate roof caving, central roof flexure, main roof fracturing, and high strata flexure.

3 ) It is inferred that the immediate roof is 3.1 times the thickness of equal mining height, and the main roof is 2.7 times the thickness of equal mining height in the gangue backfill mining in $1302 \mathrm{~N}-1$ working face.

\section{Acknowledgements}

The authors would like to acknowledge the support and contribution from the School of Resources, Environment and Safety Engineering, Hunan University of Science and Technology, China. This research was funded by the National Natural Science Foundation of China (51504096, 51874133) and the Key Technological Projects for Prevention and Control of Major Accidents in Safety Production (Shandong-0002-2016AQ).

\section{References}

[1] Liu J. G., Zhao L. T. Theory of water protection and practice application in mining based on the backfilling mining technology. Journal of China Coal Society, Vol. 39, Issue 8, 2014, p. 1545-1551.

[2] Miao X. X., Ju F., Huang Y. L., et al. New development and prospect of backfilling mining theory and technology. Journal of China University of Mining and Technology, Vol. 44, Issues 3, 2015, p. 391-399.

[3] Zhao Y. L., Zhang L. Y., Wang W. J., et al. Cracking and stress-strain behavior of rock-like material containing two flaws under uniaxial compression. Rock Mechanics and Rock Engineering, Vol. 49, 2016, p. 2665-2687.

[4] Yu W. J., Wang W. J. Strata movement induced by coal-pillar under three circumstances exchanged by gangue backfill and quadratic stability law. Chinese Journal of Rock Mechanics and Engineering, Vol. 30, Issue 1, 2011, p. 105-112.

[5] Miao X. X., Qian M. G. Research on green mining of coal resources in China: current status and future prospects. Journal of Mining and Safety Engineering, Vol. 26, Issue 1, 2009, p. 1-14.

[6] Zhao Y. L., Zhang L. Y., Wang W. J., et al. Separation of elastoviscoplastic strains of rock and a nonlinear creep model. International Journal of Geomechanics, Vol. 18, 2018, p. 04017129.

[7] Wang J. C., Yang S. L., Yang B. G., et al. Simulation experiment of overlying strata movement features of longwall with gangue backfill mining. Journal of China Coal Society, Vol. 37, Issue 8, 2012, p. 1256-1262.

[8] Zhang J. X., Li J., An T. L., et al. Deformation characteristic of key stratum overburden by raw waste backfilling with fully-mechanized coal mining technology. Journal of China Coal Society, Vol. 35, Issue 3, 2010, p. 357-362.

[9] Miao X. X., Zhang J. X. Analysis of strata behavior in the process of coal mining by gangue backfilling. Journal of Mining and Safety Engineering, Vol. 24, Issue 4, 2007, p. 379-382.

[10] Miao X. X., Mao X. B., Hu G. W., et al. Research on broken expand and press solid characteristics of rocks and coals. Journal of Experimental Mechanics, Vol. 12, Issue 3, 1997, p. 394-399.

[11] Zhao Y. L., Zhang L. Y., Wang W. J., et al. Transient pulse test and morphological analysis of single rock fractures. International Journal of Rock Mechanics and Mining Sciences, Vol. 91, 2017, p. 139-154.

[12] Zhang Z. N., Miao X. X., Ge X. R. Testing study on compaction breakage of loose rock blocks. Chinese Journal of Rock Mechanics and Engineering, Vol. 24, Issue 3, 2005, p. 451-455.

[13] Zhao Y. L., Zhang L. Y., Wang W. J., et al. Creep behavior of intact and cracked limestone under multi-level loading and unloading cycles. Rock Mechanics and Rock Engineering, Vol. 50, Issue 6, 2017, p. 1409-1424.

[14] Zhang W. H., Zhang J. X., Zhao J. S., et al. Research on waste filling technology and it's matching equipment in coal mining. Journal of Mining and Safety Engineering, Vol. 24, Issue 1, 2007, p. 79-83.

[15] Song Z. Q., Cui Z. D., Xia H. C., et al. The fundamental theoretical and engineering research on the green safe no coal pillar mining model by mainly using coal gangue backfill. Journal of China Coal Society, Vol. 35, Issue 5, 2010, p. 705-710. 
[16] Chen J., Du J. P., Zhang W. S., et al. An elastic model of overlying strata movement during coal mining with gangue back-filling. Journal of China University of Mining and Technology, Vol. 41, Issue 1, 2012, p. 14-19.

[17] Xu P., Zhou Y. J., Zhang M. X., et al. Analysis of overburden fracture development in thick loose bedrock mining. Journal of Mining and Safety Engineering, Vol. 32, Issue 4, 2015, p. 617-622.

[18] Miao X. X., Zhang J. X., Guo G. L. Study on waste-filling method and technology in fully-mechanized coal mining. Journal of China Coal Society, Vol. 35, Issue 1, 2010, p. 1-6.

[19] Zhao Y. L., Tang J. Z., Chen Y., et al. Hydromechanical coupling tests for mechanical and permeability characteristics of fractured limestone in complete stress-strain process. Environmental Earth Sciences, Vol. 76, 2017, p. 24.

[20] Xu J. L., Wang X. Z., Liu W. T., et al. Effects of primary key stratum location on height of water flowing fracture zone. Chinese Journal of Rock Mechanics and Engineering, Vol. 28, Issue 2, 2009, p. 380-385.

[21] Miao X. X., Zhang J. X. Key technologies of integration of coal mining-gangue washing-backfilling and coal mining. Journal of China Coal Society, Vol. 39, Issue 8, 2014, p. 1424-1433.

[22] Zhu C. Q., Zhou Z., Li Q. F., et al. Experimental study on the compression properties of gangue. Journal of Hunan University of Science and Technology (Natural Science Edition), Vol. 30, Issue 4, 2015, p. 1-6.

[23] Liu J. G., Zhao Q. B. Comprehensive mechanized solid filling mining technology under buildings in Xingtai Coal Mine. Coal Science and Technology, Vol. 38, Issue 3, 2010, p. 18-21.

[24] Ma Z. G., Gu R. X., Huang Z. M., et al. Experimental study on creep behavior of saturated disaggregated sandstone. International Journal of Rock Mechanics and Mining Sciences, Vol. 66, Issue 1, 2014, p. 76-83.

[25] Zhao Y. L., Zhang L. Y., Wang W. J., et al. Modeling of non-linear rheological behavior of hard rock using triaxial rheological experiment. International Journal of Rock Mechanics and Mining Sciences, Vol. 93, 2017, p. 66-75.

[26] Zhao Y. L., Wang Y. X., Wang W. J. Modeling of rheological fracture behavior of rock cracks subjected to hydraulic pressure and far field stresses. Theoretical and Applied Fracture Mechanics, Vol. 101, 2019, p. 59-66.

[27] Cao P., Liu T. Y., Pu C. Z. Crack propagation and coalescence of brittle rock-like specimens with pre-existing cracks in compression. Engineering Geology, Vol. 187, 2015, p. 113-121.

[28] Zhang Q., Zhang J. X., Huang Y. L., et al. Backfilling technology and strata behaviors in fully mechanized coal mining working face. International Journal of Mining Science and Technology, Vol. 22, Issue 2, 2012, p. 151-157.

[29] Huang Y. L., Zhang J. X., Zhang Q., et al. Strata movement control due to bulk factor of backfilling body in fully mechanized backfilling mining face. Journal of Mining and Safety Engineering, Vol. 29, Issue 2, 2012, p. 162-167.

[30] Xu J. M., Zhang J. X., Huang Y. L., et al. Experimental study and application of compaction deformation characteristics of fully mechanized filling waste-fly ash. Journal of Mining and Safety Engineering, Vol. 28, Issue 1, 2011, p. 158-162.

[31] Guo G. L., Miao X. X., Cha J. F., et al. Preliminary analysis of subsidence control effect of waste filling mining in longwall working face. China Science and Technology Papers Online, Vol. 11, 2008, p. 805-809.

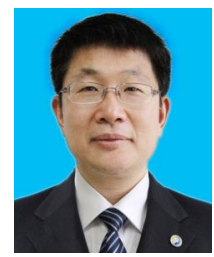

Guangjing Sun received M.S. degree in College of Mining and Safety Engineering from Shandong University of Science and Technology, Qingdao, China, in 2012. He is currently studying for the Ph.D. degree in School of Resource and Environment and Safety Engineering from Hunan University of Science and technology. His current research interests include strata control processing and prevention of dynamic disaster. 
Tao Feng received Ph.D. in School of Central South University, Changsha, China, in 1999. He has been an Associate Professor in School of Resource and Environment and Safety Engineering from Hunan University of Science and technology. His current research interests include complex coal seam mining and rock dynamics.



Jinhai Liu received Ph.D. in School of Civil and Environmental Engineering from University of Science and Technology Beijing, Beijing, China, in 2013. He has been an Associate Professor in North China Institute of Science and Technology. His current research interests include strata control processing and prevention of dynamic disaster. 